\title{
The Impact of Teenage Pregnancy on Academic Performance of Grade 7 Learners at a School in the Zambezi Region
}

\author{
Eugene L. Maemeko*, David Nkengbeza, Traphinah M. Chokomosi \\ University of Namibia, Windhoek, Namibia \\ Email: *emaemeko@unam.na
}

How to cite this paper: Maemeko, E.L., Nkengbeza, D. and Chokomosi, T.M. (2018) The Impact of Teenage Pregnancy on Academic Performance of Grade 7 Learners at a School in the Zambezi Region. Open Journal of Social Sciences, 6, 88-100. https://doi.org/10.4236/jss.2018.69006

Received: May 22, 2018

Accepted: September 2, 2018

Published: September 5, 2018

Copyright (c) 2018 by authors and Scientific Research Publishing Inc. This work is licensed under the Creative Commons Attribution International License (CC BY 4.0).

http://creativecommons.org/licenses/by/4.0/

\begin{abstract}
The Namibia Demographic Survey in 2013 revealed that about one out of five teenagers aged 15 to 19 were either pregnant or had given birth. The United Nations report for the same year believes that about 127 girls get pregnant every day in Namibia. The aim of this article was to find out the impact of teenage pregnancy on academic performance of Grade 7 learners at a school in the Zambezi Region. A qualitative research method was used in this article and two teachers and 4 pregnant learners were interviewed. The findings for this study revealed the reasons why these teenagers get pregnant as follows: lack of parental care and control, lack of some material needs, poor peer guidance, lack of sex education, and the influence of alcohol and drug abuse. The impact of teenage pregnancy on academic performance included poor academic performance after the pregnancy, increase dropout because of pregnancy related issues and negative feeling on schooling.
\end{abstract}

\section{Keywords}

Teenage Pregnancy, Zambezi Region, Grade 7 Learners, Academic Performance

\section{Introduction}

Spencer [1] defines teenage pregnancy as pregnancy occurring in a young girl between the age of 13 and 19, whereas Macleod [2] defines it as a social problem in which adult practices and functions (sexual intercourse, reproduction, mothering) are displayed by a person who, owing to her age and developmental status, is not-yet-adult, that is, adult, but not adult, child, but not child. Pregnancies are a result of sexual activities either voluntary or not. One of the most 
traumatic and devastating effects on teenage pregnancy is making it difficult for the girl to continue with her education.

In Namibia, more than 46,000 teenagers were pregnant in 2013 which translates into about 127 girls every day a United Nations report revealed. According to the United Nations Population Fund (UNFPA) these statistics were released in commemoration of World Population Day, celebrated on 11 July every year. When the statistics were compiled, there were 245,431 teenage girls in Namibia aged between 15 and 19. The report said the figures are higher in some regions, and Zambezi is no exception with $20 \%$ of teenagers in some rural areas becoming mothers earlier than their counterparts in urban areas [3].

More so, the fact that most parents pay less attention to their children, coupled with the fact that teenagers today are growing up in a culture way in which peers, television and motion pictures, music and magazine often transmit either covert or overt message on unmarried sexual relationship (specifically those involving teenagers) are commonly accepted and at times expected behavior have contributed immensely to the moral decadence rampant among our teenagers. Even though the educational system promotes education as a pillar of responsible sexual behavior and specific information about the consequences of sexual intercourse (including teenage pregnancy, sexual transmitted diseases and psychological effects) that are frequently not offered at home, or in the community settings. Students seem not to be doing well in this domain as many get pregnant every year. Therefore, much of the sex education teenagers receive filters through misinformed and/or unified peers.

One major contemporary social problem confronting most countries in the world is teenage pregnancy. From the first world countries such as the United states to the third world countries, this problem has been a source of worry for policy makers, social workers and other human service providers due to its negative repercussions on the girl-child Kaufman [4].

\subsection{Problem Statement}

It has been observed that teenage pregnancy has remained persistent in our local communities due to various contributing factors and has had negative impacts on the life of the teenagers involved. Panday et al. [5] affirm that teenage mothers are unlikely to complete high school education (i.e. secondary school education). The non-completion of a secondary school education limit the life earning potentials among the teenage population, which could perpetuate the cycle of impoverishment among them. Based on this, the study is therefore, concerned with the identification and assessment of the causes and impact of teenage pregnancy on the academic performance of the teenagers at a selected school as well as exploring various strategies through which it can be avoided, or tackled in local government areas, so as to enable teenage mothers and fathers as well as sexually active teenagers who would have dropped out of school due to teenage pregnancy to achieve their educational and career goals. Understanding the impact of 
teenage pregnancy differences in the background of the learners on their academic performances prompts the researchers to address the following probing question:

\subsection{Research Questions}

The research questions for this article are as follows:

1) What is the impact of teenage pregnancy on the academic performance of Grade 7 learners at the selected school?

2) How do we limit the impact of teenage pregnancy among learners at the case school?

\subsection{Significance of the Study}

The significance of the study is to shade light in our current pregnancy policy and how to improve it and to ensure that regulations are forced at ground level for school girls who get pregnant to be re-integrated in the mainstream educational system. In most cases, schoolgirls who become pregnant in rural areas and towns have to either resort to unsafe abortions or they face official school expulsion due to pregnancy. According to the Namibian policy, a girl may continue with her education after giving birth, provided that the principal if no social worker is readily available is satisfied that the infant will be cared for by a responsible adult. Furthermore the learner-parent and her parents, primary caretaker or guardian provide a signed statement with an exposition on how the infant will be cared for and an undertaking to maintain open communication with the school. The learner may choose to return to school as soon as she can supply the specified documentation or she may choose to take a longer period of leave up to a maximum of one calendar year from the date on which she left school because of the pregnancy. She may take a longer leave of absence, but then her place at school will not be reserved. In order to ensure that her place at school will be reserved during her leave, the learner and her family must maintain clear communication with the school regarding the date on which she intends to return.

Those most likely to benefit from the findings of this study are the Ministry of Education and the school management, especially in the formulation and strengthening of policies that guard teenage pregnancies in schools and the possible re-admission of the affected girls back to school. While in many settings, rules are currently being liberalized to provide for possibility of re-entry, the number of those returning back to school is still very low. And due to the fact that a pregnant schoolgirl has to choose between dropping out of school and undergoing an abortion in order to remain in school, poses a high cost associated with becoming pregnant while still in school. On the other hand, boys who get the girls pregnant do not face the same risks.

In the Namibian educational systems the ministry of education has also included life skill education programs in their school curriculum in an attempt to 
educate adolescents about the consequences and responsibilities associated with sexual activity. The high rates of schoolgirl pregnancies suggest that these life skill programs have their shortcomings and indicate that educational policies should be used not only to reduce the incidence of schoolgirl pregnancies but also to assist pregnant schoolgirls to complete their education. For example at the research site traditionally teenage pregnancy has been accepted even celebrated as transition for young girls becoming women in their community.

\section{Literature Review}

\subsection{Introduction}

Recent studies have investigated the degree to which pregnancy related school dropout was a major cause of gender differences in educational attainment [6]. The aim of this study was to find out the impact of teenage pregnancy on the academic performance of Grade 7 learners at a school in the Zambezi Region of Namibia.

According to the United Nations Population Fund (UNFPA) rural teenage girls are at a higher risk of getting pregnant than their urban counterparts and this is attributed to the fact that rural teenage girls only have primary-level education, while girls in urban areas are better educated. Apart from the academic factor, the report also said some girls do not know how to avoid falling pregnant, while others feel shy or are ashamed to access contraceptives.

The use of contraceptives among young people aged between 15 and 19 is $24 \%$ in rural areas, compared to a national contraceptive prevalence rate of $50 \%$. However, sexual activity can be compounded by poverty, peer pressure or lack of education [7].

Barmao, Nyaga and Lelan [7] feel that lack of resources might also force girls to become involved in sexual activities in an effort to get material needs and food.

Furthermore, the results of a study on the teenage pregnancy rate conducted in the Kavango Region, by the United States Agency for International Development (USAID), 2011, revealed that the teenage pregnancy rate in Kavango like Zambezi region was double the national average, standing at 34 per cent among the 15 to 19 -year-old age group. The study also found that the main causes of teenage pregnancies were lack of education and poverty. The study showed that 91 per cent of pregnancies among teenagers were unwanted, while 98 per cent of young people were informed about contraceptives, but only $8.7 \%$ used it [3].

The negative attitude of nurses, who apparently victimized girls whenever they went to health centers seeking contraceptives, was also found to be a contributing factor. The study found that condom use was very low at 36 per cent, while they were readily available. Teenage pregnancy and motherhood is a serious concern in both developed and developing countries, where girls have become mothers suffers ridicule, stigmatization and abuse from both parents and teachers (Barmao, Nyaga \& Lelan [7]). According to Kaufman [4], teenage 
pregnancy and teenage parenthood are the major contributing factors for most girls to drop out of school. Theron and Dunn [8] also concurs with Kaufmann [4] by adding that adolescent and child bearing is quite disruptive to educational process of girls and as the result, many teen mothers leave school and never return. Teenage pregnancy is one of the social ills that affect society. The existence of teenage pregnancy affects the development and education of the girl-child (Gyan [9]). This is attributable to the girls' age and the absence of any consistent means of support to care for the children and themselves when they should have been in school. It is alleged that teenage pregnancy and its associated motherhood are characterized with shame, disgrace, and school dropout, and sometimes end of the individual's dreams of achieving higher pursuits [9].

\subsection{Challenges of Teenage Motherhood}

Gyan [9] asserted that teenage pregnancy has a lot of social consequences which include school drop-out or interrupted schooling, falling prey to criminal activity, abortion, ostracism, and child neglect, school adjustment difficulties for their children, adoption, and lack of social security, poverty, repeated pregnancy and negative effects on domestic life. Teenage mothers, particularly at my research site continue to be constrained by pregnancy in that they fail to participate in educational activities [6]. More so, they fail to complete their schooling because they are over their academic work because they are mothers first and learners later. Supporting this Chilisa [10] asserted that a pregnant school girl is being challenged with options like taking days off school just to be with her baby, reentry and continuation. All of these options that they face have both principled and practical difficulties. Managing as well as caring for an infant and devoting much time to school work is a great challenge for these teen parents. Studies have shown that the birth of a child marks the end of schooling for these teen parents Grant and Hallman [11]. There are however, factors that can influence whether or not a school girl should proceed with her schooling after giving birth. These are: the ability for her to continue managing logistics and finances associated with mothering and schooling at the same time Kaufmann [4]. While pregnancy has become the girls' major factor for school dropouts, issues of social, economic and cultural aspects has of recent become complex factors in this regard.

\subsection{Effects of Teenage Pregnancy on Education}

In a research by Gyan [9] he asked the participants to indicate whether they were still in school during the period of the study and their responses were that about five learners were not in school during data collection and this information has to be given out by those that were in school at the time while two of them indicated that they were in school. This implies that teenage pregnancy can be a cause as well as an effect of school dropout. That is being in school often prevent teenagers from getting pregnant so those who have dropped out of school are likely to fall prey to teenage pregnancy [9]. 
Hosie [12] also found out that bullying by teachers or other students were instrumental in their dislike of school. Those students whose attendance are poor and who dislike school prior to pregnancy have a negative attitude from their schools on disclosure of their condition and are less likely to remain in school than those who had good attendance beforehand [12]. Studies on Teenage pregnancy suggested that statistically, young mothers face a life of poverty, have lower levels of education and have less opportunity in the workplace than non-parenting teens. She found that research on teen pregnancy prevention usually focuses on the negative aspects of being a teen parent. It is also alleged that the relationship between teenage pregnancy and education goes in both directions. Teenagers who become pregnant are more likely to drop out of school and teenagers who drop out of school are more likely to become pregnant Kaufmann [4].

\subsection{The Conceptual Framework on the Impact of Teenage Pregnancy on Learners' Academic Performance}

Figure 1 is a Conceptual Framework on the impact of teenage pregnancy on learners' academic performance at a selected school in Zambezi region in Namibia. From the figure above, seven factors have direct impact on the academic performance of learners and they include dual responsibilities, poor physical and mental health, Reduction in educational attainment, self-hate and neglect, social isolation, reduced self-esteem and low class performance among others.

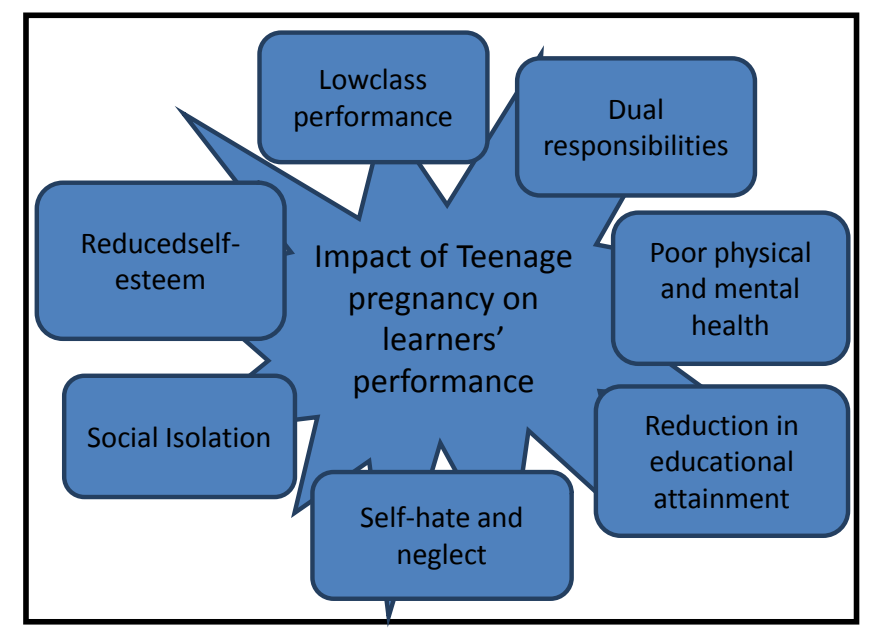

Figure 1. Impact of Teenage pregnancy framework.

\section{Methodology}

\subsection{Research Design}

A qualitative research design was used in this study because the researchers wanted to find out the impact of teenage pregnancy on academic performance of Grade 7 learners. Patton [13] states that qualitative research uses a naturalistic approach that seeks to understand phenomena in context-specific setting, such 
as "Real world settings where the researcher does not attempt to manipulate the phenomenon of interest". Since this study sought to understand teenage pregnancy and its effects on the academic performance of learners, the researchers found qualitative design relevant. Qualitative research is an enquiry in which researchers collect data in face-to-face situations by interacting with selected persons in their settings, describing and analyzing people's individual and collective social actions, beliefs, thoughts, and perceptions McMillan \& Schumacher [14].

\subsection{Population and Sample}

The population consisted of teachers and teenage mothers. Purposive sampling was also used. The sample for the study will be six participants in total, made up of 2teenage mothers already in school and also the 2 expecting teenage mothers in grade 7 at the school and 2 teachers who were one male and one female.

\subsection{Data Collection Instrument}

\section{Interviews}

This study used in-depth interviews. This instrument gave the researchers the platform to ask open ended questions about teenage pregnancy so that the participants will be able to explain issues concerning this problem being researched (De Vos et al. [15]). 2 Teachers, 2 expecting teenage mothers and 2 teenage mothers were interviewed.

\subsection{Data Collection Procedure}

The unstructured one-to-one in-depth interviews was conducted through visiting the respective school and making personal contact with the selected participants, preferably in a quiet place such as an office in order to avoid disturbances. Interviews carried out after working hours at the school. In order to ensure completeness and reliability of information, interview sessions will be recorded on a provided paper.

\subsection{Data Analysis}

After collecting the data, we used discovery and interim analyses strategies to analyze and code the data (McMillan \& Schumacher [14]). The obtained results was then analyzed and interpreted. The discovery analysis strategy was also used to develop tentative and preliminary ideas about the issues under investigation during data collection. This was done by writing summaries and comments on interviews to identify possible themes focus on the study.

\section{Findings and Discussions}

\subsection{Factors that Lead to Teenage Pregnancy}

\subsubsection{Teachers Responses}

In respect to factors that lead to teenage pregnancy Teacher A said that:

Parental relationship and atmosphere within their homes pushes teenagers 
to seek for love and care from their male classmates which always make them engage in insensible sex which may consequently lead to teenage pregnancy. It is also marked that lack of materials make them engage in pre-mature sexual relationship in order to get money and food of which they end up being victims of teenage pregnancy. (TA)

To add on what teacher A said, Teacher B responded by saying:

It is marked that peer guidance contributes greatly to teenagers' connection in early sex. I have confidence that peer pressure is the main cause of teenage pregnancy because a number of teenagers' depend on their peers for information that makes them fall victim to teenage pregnancy. (TB)

Still on the second objective of finding or recognizing the factors that leads to teenage pregnancy two (2) Expecting Teenage Mothers. Expecting Teenage Mother A (ETMA) responded by saying:

I have been careless in sexual activities that regularly happen in youth whereby I didn't have straight-forward information about sex and I was also not aware of ways on how I can prevent myself from getting pregnant. The relationship that I had with my parents was bad this stimulated me to seek for comfort, acceptance and support through sexual activities. The use of alcohol and drug abuse also contributed to my pregnancy because I don't make right decisions when I'm drunk. (ETMA A)

In response to the question regarding the factors that leads to teenage pregnancy, there was a similar understanding from Expecting Teenage Mothers whereby Expecting Teenage Mother B (ETMB) also said she was irresponsible in sexual behavior occurring among youth. Furthermore, she also said that the exposure to suggestive or explicit media, films, magazines, music that may influence adolescent sexual behavior, also caused them to engage in sexual activities before they were ready.

Teenage Mother A (TMA) stated that it is not that teenagers only get pregnant by their classmates but also their male teachers contribute in the drop out of the girl child. Strongly TMA agreed with both TA and TB that parental relationship and peer pressure contribute to teenage pregnancy. Teenage Mother B agreed with both participants and added that early pregnancy may be seen as a normal occurrence, the outcome of adolescent fertility and an indication of one's motherhood. Poverty also plays a vital role in inducing teenage pregnancy among learners.

\subsubsection{The Views of Teenage Pregnant Learners}

According to learners interviewed, they believed that their lack of knowledge about sexuality and reproductive education among them was one of the factors that led to teenage pregnancy. They blamed lack of parental care, control and supervision, for some single parent families who are unable to properly support their families as being some of the reasons that led to some of them getting 
pregnant. They said that most parents neglected their own children by not giving them support to satisfy their needs, risked seeing them seeking comfort, acceptance and consolation through sexual activities. Alcohol and drug abuse was another factor according to these learners. They explained that after being influenced by alcohol or drug they make uncompromised decisions and subsequently getting pregnant.

\subsection{The Impact of Teenage Pregnancy on the Education of the Girl-Child}

Teenage pregnancy is a serious issue that may negatively impact the future of a girl child. TA and TB responded that teens usually lack skills needed to handle their pregnancy and motherhood. Teachers also reported that when comparing a learner's performance before and after pregnancy there is a huge difference in their academic performance, because when they are pregnant they miss a lot of schoolwork such as lessons, home works, tests and so forth. Causes specified by the teachers include truancy due to pregnancy related issues and the sense of tiredness especially when the girl is about to give birth. Some educators maintain that it will depend on the learner's intellectual ability whether the academic performance of a pregnant teenager drops or not. One educator gave a scenario where a very brilliant learner fell pregnant and this negatively affected her performance resulting in failure at the end of the year. The following verbal quotes support the above issues that emerged from the educators responses:

Absolutely, they perform very poorly, because pregnancy is a hell lot of job on itself (TB). I had an experience whereby a learner was brilliant in class before she fell pregnant, immediately when she was in that situation everything changed completely (TA).

Moreover teenage mothers also start developing negative attitude toward their school work whereby they will start thinking about the responsibility of their kids and forgetting about their future. As a result a teenager may suffer an emotional disaster if she becomes pregnant and does not want the baby. This tragedy may lead to unforeseen behavior of attempting abortion or a suicide. Expecting teenage mothers will be left behind with their schoolwork by the time they are on maternity leave. To add on the impacts of teenage pregnancy, expecting mothers end with school dropout because of the fear of embarrassment from the fellow classmates.

Findings in this study revealed that the impact of teenage pregnancy on the education of the girl child, expecting mothers and mothering teenagers at school level generally perform poorly as compared to their performance before. This centered on lack of experience in motherhood, dual responsibilities, poor health status, and lack of parental support. The present study concurs with that of Swann et al. [16] who advocated that teenage pregnancy and early motherhood can be associated with poor educational achievement, poor physical and mental health, social isolation, poverty and related factors. In a similar vein, Duncan 
[17] maintains that teenage parents experience reduction in their education attainment compared to teenagers who are not parents. The reasons behind poor academic performance of pregnant and mothering teenagers as revealed by the findings of this study are among others, dual responsibilities the affected learners are faced with.

It is clear from Table 1 that performance of learners before and after pregnancy varies in that before they fell pregnant, at least 2 learners were excellent with their academic performance, 5 were very good and those that performed well were 19 and 4 on average. After pregnancy, there was no excellent and very good. Only 3 were good, 10 were average and those below average were 17 . This is indicative of how pregnancy can in fact impact the once performing learners.

Table 1. Learners' academic performance before and after pregnancy (Gyan [9]).

\begin{tabular}{ccc}
\hline Academic performance & Before pregnancy & After pregnancy \\
\hline Excellent & 2 & 0 \\
Very good & 5 & 0 \\
Good & 19 & 3 \\
Average & 4 & 10 \\
Below average & 0 & 17 \\
Total & 30 & 30 \\
\hline
\end{tabular}

\subsection{How to Limit the Impact of Teenage Pregnancy among Learners}

On the establishment of addressing teenage pregnancy among learners TA noted that, a life skill teacher should have sex talks (sex education) with learners. The life skill or school counselor must also provide counselling to both expecting and teenage mothers concerning their current situation. The school must teach teenagers about abstinence, especially those that have not yet started with sexual relationships. This notion centered on calling religious leaders to schools to preach to learners about religious principles which include sex before marriage as sinful. The study established that the rate of teenage pregnancy at a selected school can be reduced and prevented through a number of strategies. This centered on introducing sex education, approaching learners differently considering their age differences, and net-working with other community stakeholders, for example, social workers, nurses, educational psychologists, and religious leaders. Various strategies to prevent teenage pregnancy were suggested in this study, for example, making condoms readily available to secondary schools, contraceptive usage, and abstinence. Literature by Irvine, Bradley, Cupples and Booham [18], Slowiski [19] and O'Donnel and Wyneken [20] confirm the introduction of sexuality education to learners as helpful. Slowiski [19] advocates that sex education programs are most effective if they provide accurate information, and include decision-making, assertiveness and negotiation skills, as well as life skills. The 
issue of condoms being made available to schools as revealed by this study concurs with the findings by O'Donnel and Wyneken [20] when they postulate that condoms and other forms of contraception are to be made available to teens through condom availability programs around school, teen health centers, and clinics-productive health services and sex education.

\section{Conclusion}

Teenage pregnancy and school attendance do not go well together in that the latter has a detrimental effect on their education and their future plans in school. This is because the teenage mothers attend school irregularly and sometimes drop out of school due to the parenting role which they are now into. While this study revealed that teenage pregnancy and mothering resulted in poor school performance at the case school and has subsequently led to drop out of school, it calls for the policy makers and the Directorate of Education in Zambezi region to hasten the remedial actions to curb this unfortunate situation.

\section{Recommendations}

Based on the findings of this study, it is recommended that pregnant learners should be encouraged to study hard in order to improve their academic performance in the classroom. Educators should teach them study skills, provide individual support programme (ISP) in case the pregnant learner had challenges related to pregnancy ailments and is unable to complete certain tasks. Educators should enroll for Special Needs education qualifications so that they acquire knowledge on how to support and include learners that are physically, mentally and emotionally challenged, including pregnant learners in their classroom situations of ordinary schools, to help these affected learners perform better academically like other learners who have not fallen pregnant.

1) School-based sexuality education: An effective sexuality education programme at schools can delay the initiation of sex, reduce the frequency of sex and number of partners and increase contraceptive use and risky sexual behavior. The best sexuality education programme for teenage (schoolgirl) pregnancy requires sober reflection on the complexity of the problem [5].

More so, the curriculum for school-based sexuality education should, inter alia, include the Information on reproductive health problems such as Sexually Transmitted Infections (STIs), HIV/AIDS and the health risks of teenage pregnancy. Give them advice about the different contraceptive methods that are available and knowledge about their correct use. Intervention procedures that focus on the risky sexual behavior of adolescent learners should be taught. For the effective implementation of the curriculum the Ministry of Education should secure support from health Ministry and appropriate community organizations. Also provide monitoring, supervision and support. Furthermore The Ministry of Education should facilitate Training of school management teams in methods to deal with schoolgirl pregnancy. Workshops to school boards on how to deal with 
schoolgirl pregnancies should be initiated. The establishment of schoolgirl clubs and Learner Representative Councils (LRCs) where the issues relating to schoolgirl pregnancies can be discussed will help.

2) School linked health clinics: Through this recommendation the government in collaboration with Education departments and the community should establish health clinics that are linked to schools. Health clinics must be easily accessible to the school community. It should be on the school premises, close to the schools or transport should be provided if it is not within easy reach of the learners. Social workers should be available at the clinics to support pregnant schoolgirls, schoolgirl mothers and their babies.

The educators should consider giving emotional support to pregnant teenagers by showing them love and empathy. Negative remarks about pregnant learners in the classroom situation should be avoided at all costs. Advices or corrections pertaining to the state of affairs of pregnant teenagers should be done in camera or privately by the teacher, not in the presence of other learners who are not pregnant. This will promote good relationships between educators and pregnant teenagers.

Learners who are not pregnant in school should avoid discriminating against those that are pregnant. Educators should teach learners who are not pregnant never to tease and arouse the temper of those that are pregnant so that both learners should maintain harmonious relationships between themselves. This will alleviate the problem of low self-esteem and inferiority complex on pregnant teenagers in the classroom situation and the school premises. Further research on the impact of teenage pregnancy should be conducted to determine the impact of teenage pregnancy on the academic performance in junior and senior secondary school learners as perceived by the teenage mothers themselves and their classmates.

\section{Conflicts of Interest}

The authors declare no conflicts of interest regarding the publication of this paper.

\section{References}

[1] Spencer, S. (2011) The eHow: Facts about Teenage Pregnancy. http://www.ehow.com/about_4619346_teen

[2] Macleod, C. (2011) “Adolescence”, Pregnancy and Abortion: Constructing a Threat of Degeneration. Routledge, New York.

[3] The Namibian (2016) The Namibian. 127 Namibian Teenagers Fall Pregnant Daily. https://www.namibian.com.na/153170/archive-read/127-Namibian-teenagers-fall-p regnant-daily

[4] Kaufmann, C. (2001) Adolescent Pregnancy and Parenthood in South Africa. Studies in Family Planning, 32, 147-160. https://doi.org/10.1111/j.1728-4465.2001.00147.x

[5] Panday, S., Makiwane, M., Ranchod, C. and Letsoalo, T. (2009) Teenage Pregnancy in South Africa with Specific Focus on School Going Learners. HSRC, Pretoria. 
[6] Eloudou-Enyegue, P.M. (2004) Pregnancy-Related Dropouts and Gender Inequality in Education: A Life-Table Approach and Application in Cameroon. Demography, 41, 509-528. https://doi.org/10.1353/dem.2004.0021

[7] Barmao, K.C., Nyaga, J.K. and Lelan, J.K. (2015) Impact of Teenage Motherhood on the Academic Performance in Public Primary Schools in Bungoma County, Kenya. International Journal of Educational Administration and Policy Studies, 7, 61-71.

[8] Theron, L. and Dunn, N. (2006) Coping Strategies for Adolescent Birth-Mothers Who Return to School Following Adoption. South African Journal of Education, 26, 491-499.

[9] Gyan, C. (2013) The Effects of Teenage Pregnancy on the Educational Attainment of Girls at Chorkor, a Suburb of Accra. Journal of Educational and Social Research, 3, No. 3. https://doi.org/10.5901/jesr.2013.v4n3p53

[10] Chilisa, B. (2002) National Policies on Pregnancy in Education Systems in Sub-Sahan Africa: The Case of Botswana. Gender and Education, 14, 21-35. https://doi.org/10.1080/09540250120098852

[11] Grant, M.J. and Hallman, K.K. (2008) Pregnancy-Related School Dropout and Prior School Performancein Kwazulu-Natal, South Africa. Studies in Family Planning, 39, 369-382. https://doi.org/10.1111/j.1728-4465.2008.00181.x

[12] Hosie, A.C.S. (2007) "I Hated Everything about School": An Examination of the Relationship between Dislike of School, Teenage Pregnancy and Educational Disengagement. Social Policy and Society, 6, 333-347. https://doi.org/10.1017/S1474746407003661

[13] Patton, M.Q. (2002) Qualitative Evaluation and Research Methods. 3rd Edition, Sage Publications, Inc., Thousand Oaks, CA.

[14] McMillan, J.H. and Schumacher, S. (2006) Research in Education: Evidence-Based Inquiry. 6th Edition, Pearson Education, Inc., USA.

[15] De Vos, A.S., Strydom, H., Fouché, C.B. and Delport, C.S.L. (2005) Research at Grass Roots: For the Social Science Professionals. 3rd Edition, Van Schaik, Pretoria.

[16] Swann, C., Bowe, K., McCormick, G. and Kosmin, M. (2003) Teenage Pregnancy and Parenthood: A Review of Reviews. Evidence Briefing. Health Development Agency (HAD).

[17] Duncan, A. (2011) Teenage parents and their Educational Attainment. TEXAS Comprehensive Centre.

[18] Irvine, H., Bradley, T., Cupples, M. and Booham, M. (1997) The Implications of Teenage Pregnancy and Motherhood for Primary Health Care: Unresolved Issues. The British Journal of General Practice, 47, 323-326.

[19] Slowiski, K. (2001) Unplanned Teenage Pregnancy and the Support Needs of Young Mothers. Department of Human Sciences, South Australia.

[20] O’Donnell, L. and Wyneken, C. (2007) Strategies for Adolescent Pregnancy Prevention. The American College of Obstetricians and Gynaecologists. Washington, DC. 